\title{
Detecting the Source Location of Recent Summit Inflation via Three-Dimensional InSAR Observation of Kïlauea Volcano
}

\section{Min-Jeong Jo ${ }^{1}$, Hyung-Sup Jung ${ }^{2, *}$ and Joong-Sun Won ${ }^{1}$}

1 Department of Earth System Sciences, Yonsei University, Seoul 120-749, South Korea; E-Mails: owen009@yonsei.ac.kr (M.-J.J.); jswon@yonsei.ac.kr (J.-S.W.)

2 Department of Geoinformatics, The University of Seoul, Seoul 130-743, South Korea

* Author to whom correspondence should be addressed; E-Mail: hsjung@uos.ac.kr;

Tel.: +82-264-902-892; Fax: +82-264-902-884.

Academic Editors: Zhong Lu, Magaly Koch and Prasad S. Thenkabail

Received: 17 August 2015 / Accepted: 26 October 2015 / Published: 29 October 2015

\begin{abstract}
Starting on 21 April 2015, unusual activity on the summit of Kîlauea was detected. Rapid summit inflation and a rising lava lake in Halema'uma'u crater were interpreted as early signs of imminent magma intrusion. We explored the three-dimensional (3D) surface motion accompanying this volcanic event using the Interferometric Synthetic Aperture Radar (InSAR) stacking method. Multi-temporal COSMO-SkyMed X-band SAR data collected from ascending and descending orbits were processed for the time period encompassing the unrest behavior. The $3 \mathrm{D}$ displacement maps retrieved by integrating the stacked InSAR with Multiple-Aperture Interferometric SAR (MAI) measurements revealed the deformation patterns and areal coverage of this volcanic activity. The observed maximum displacements were approximately $8.2,-13.8$, and $11.6 \mathrm{~cm}$ in the east, north, and up directions, respectively. The best-fit model for the mechanism causing the surface deformation was determined via ten thousand simulations using the 3D surface deformation as the input. When compared to the results of a previous study, the 3D-based modeling produced more precise model parameter estimates with markedly lower uncertainties. The optimal spheroid magma source was located southwest of the caldera, lying at a depth of approximately $2.8 \mathrm{~km}$ below the surface. Precise model parameter estimates produced using the 3D-based modeling will be helpful in understanding the magma behavior in Kîlauea's complex volcanic system.
\end{abstract}


Keywords: Kîlauea Volcano; magma intrusion; InSAR; 3D displacements;

3D-based modeling

\section{Introduction}

The Killauea volcano, one of the youngest and most active volcanoes in the world, showed unusual activity beginning on 21 April 2015. Kîlauea's summit inflated at an abnormal rate, and the Halema'uma' $u$ crater began to fill with a rising lava lake. The rising lava finally reached the floor of the Halema'uma' $u$ crater on 28 April, and these conditions continued for approximately two weeks until 10 May 2015. After overflowing for approximately 10 days, the lava lake began to drop along with a summit deflation starting on 10 May. Seismic activity in the southern portion of Kîlauea's summit increased sharply on 14 May and a tiltmeter began to tilt rapidly from the static state. In other words, the slope of the ground began to change due to magma dynamics beneath the southern part of Kîlauea's summit. All of these activities were interpreted as an early sign of an imminent magma intrusion into the southern portion of the Kîlauea caldera (U.S. Geological Survey reports; http://hvo.wr.usgs.gov/volcanowatch).

Interferometric Synthetic Aperture Radar (InSAR) is the most powerful technique for the measurement of surface displacements using imaging-based approaches. It has been used to investigate enormous volcanic activities in recent decades [1-7]. To map realistic surface motions, three-dimensional (3D) components of surface deformation have been retrieved in recent studies [6,8-10]. Several methods have been adopted to solve the 3D measurement problem, but weak resolving power in the along-track direction is the main obstacle for retrieving precise 3D displacements in most approaches.

The Multiple Aperture Interferometry (MAI) technique uses split-beam InSAR processing to provide precise measurements in the along-track direction [11,12], and this technique has opened a new chapter in SAR interferometry. The measurement accuracy of 3D displacements has been markedly improved by the MAI method, which is approximately two- to three-fold more accurate than the offset-based approach $[10,12,13]$. Using the MAI method, 3D measurements have been made of various geologic phenomena [6,14,15]. Recently, 3D measurements using multi-temporal data stacking was introduced to further improve the measurement accuracy, allowing sub-centimeter accuracy in the 3D measurements to be achieved [16].

In this study, surface deformation associated with the recent volcanic activity of the Kilauea volcano, Hawai'i, was explored by conventional InSAR and MAI techniques using a multi-temporal COSMO-SkyMed X-band SAR data set. The 3D components of the surface deformation were calculated by integrating the multi-stacked InSAR and MAI interferograms, obtained from ascending and descending orbits, respectively. Compared to the C- and L-band SAR system, the X-band SAR is difficult to apply in the MAI observation because the X-band system is affected by relatively large temporal decorrelation. Despite the potential risks of temporal decorrelation associated with the $\mathrm{X}$-band system, the powerful capability of data acquisition from COSMO-SkyMed enables us to measure the precise MAI deformation using the multi-temporal stacking approach $[17,18]$. 
Model parameter estimations of the magma source were performed using the $3 \mathrm{D}$ components of the surface deformation. Surface displacements during periods of unrest have been used to determine the geometries and volume changes of magma bodies [2,7,19-21]. By modeling geodetic observations, previous studies have demonstrated that there are at least three or four discrete magma reservoirs beneath Kīlauea's summit. Individual sources are located beneath Keanakāko'i, Halema'uma'u, and the southern caldera $[7,20,22]$. The shallow magma source below Halema'uma'u crater is at a depth of 1-2 km [7], whereas the other sources lie at depths of 2.5-4.5 km. By modeling the 3D displacements, we are able to determine that the most relevant magma source for the recent volcanic activity of Kîlauea volcano. In addition, we expect to achieve better precision in the parameter estimates by exploiting the 3D-based modeling.

\section{Study Area \& Data Sets}

\subsection{Kīlauea Volcano}

Recent volcanic activity in the Kîlauea volcano has mostly occurred on Kîlauea's summit or in the two rift zones (Figure 1). The shallow magmatic system, including magma supply, storage and transport, is closely related to impending eruption activities. The first eruption in Halema 'uma' $u$ crater on Kîlauea's summit began in March 2008, and the crater was initially $35 \mathrm{~m}$ wide. In late 2013, the crater had grown to a much larger size, i.e., $160 \mathrm{~m}$ wide and $215 \mathrm{~m}$ long [23]. The third period of the eruption started recently in April 2015. Since the magma behavior beneath Kîlauea's summit results in volcanic eruptions or seismic activity, we need to monitor the surface changes and chemical state using continuous observing systems.

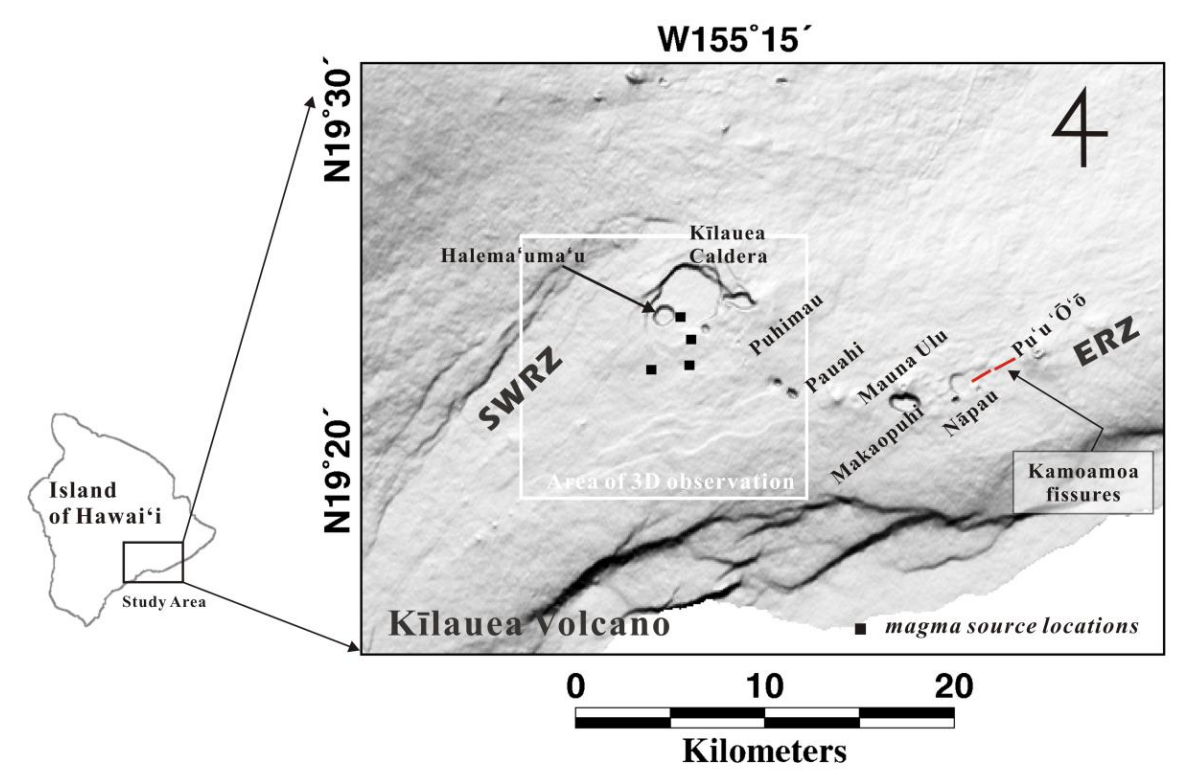

Figure 1. Shaded relief map of the Kîlauea volcano, Hawai'i, including the summit and rift zones. The white box outlines the area where 3D displacements of surface deformation were measured. Small squares indicate the magma source locations beneath Kîlauea's summit. The red line between Nāpau and $\mathrm{Pu}^{\prime} \mathrm{u}$ ' $\overline{\mathrm{O}}^{`} \overline{\mathrm{o}}$ craters represents the Kamoamoa fissure. ERZ, East Rift Zone; SWRZ, Southwest Rift Zone. 
To understand the complex magma system of the Kîlauea volcano, numerous studies have been conducted using geodetic data $[6,7,16,19,20,22]$. Surface deformation over the volcanic region is closely related to dynamic changes in magma conditions. Many of these studies investigated the characteristics of the magma sources beneath the Killauea caldera through modeling approaches [19,20,24]. In particular, Baker and Amelung (2012) suggested that the shallow magmatic system at Kîlauea's summit area can be divided into four distinct and interconnected magma reservoirs [20]. Small black squares represent the surface locations of different magma sources beneath Kîlauea's summit [20]. Most of the magma bodies lie within $5 \mathrm{~km}$ below the surface. Among them, the modeled result of a point source at $1.5 \mathrm{~km}$ depth is mostly consistent with other studies [22,25]. However, disagreement exists with regard to the number of sills and their positions associated with other sources. Thus, an investigation of the surface deformation during periods of unrest is necessary to reveal the magma system of Kīlauea.

\subsection{InSAR \& MAI Data Processing}

In this study, the measurement of Kîlauea's summit inflation was performed by co-eruptive interferometric pairs of COSMO-SkyMed acquired from ascending and descending orbits. Although the X-band SAR is limited by high temporal decorrelation due to its short wavelength, the COSMO-SkyMed SAR system is able to maximize the temporal resolution with its four-satellite constellation. We used strip-map mode images, which have a resolution of approximately $3 \mathrm{~m}$ in range and azimuth directions and a single frame is $40 \times 40 \mathrm{~km}$. Since Kīlauea's summit and rift zones lie in a single image, the measurement of 3D displacements was conducted for the area of interest. In Figure 1, the region outlined in white delineates the area investigated using $3 \mathrm{D}$ surface deformation and the focus of the magma source modeling.

Table 1 lists the interferometric pairs used in this study, with perpendicular $(\mathrm{B} \perp)$ and temporal $\left(\mathrm{B}_{\mathrm{t}}\right)$ baselines. All the reference and repeat pass images were collected before and after the period of unrest (21 April to 17 May 2015) to measure the recent magma intrusion at Kîlauea. From the data sets, eight and seven co-eruptive pairs were selected from ascending and descending orbits, respectively, to generate the conventional InSAR and MAI interferograms. Although most of the image pairs from the ascending path have perpendicular baselines shorter than $300 \mathrm{~m}$, certain pairs from the descending path have baselines longer than $400 \mathrm{~m}$ because they preserved the interferometric coherence over 0.7 at the non-vegetated area. In temporal baseline criteria, image pairs with the time durations of less than four months were used for this study.

As a first step in mapping 3D displacements of surface deformation, two forward-looking and two backward-looking single-look complex (SLC) images for the MAI processing and two full-aperture SLC images for the conventional InSAR processing were generated for each image pair. The Doppler center of each full-aperture SLC image was determined by averaging Doppler centroids of the reference and repeat path SAR images. The center frequency of the sub-aperture SLC images were determined by the fraction factor, which is the normalized squint $[11,14]$. The fraction 0.5 was applied in our MAI processing. 
Table 1. Co-eruptive interferometric pairs of COSMO-SkyMed ascending and descending data sets used in this study.

\begin{tabular}{cccccc}
\hline \multicolumn{3}{c}{ Ascending Pairs } & \multicolumn{3}{c}{ Descending Pairs } \\
\hline Acquisition Date & $\mathbf{B} \perp(\mathbf{m})$ & $\mathbf{B}_{\mathbf{t}}(\mathbf{D a y})$ & Acquisition Date & $\mathbf{B} \perp(\mathbf{m})$ & $\mathbf{B}_{\mathbf{t}}(\mathbf{D a y})$ \\
\hline 20150206_20150522 & 291.89 & 105 & $20150209 \_20150601$ & -241.63 & 112 \\
20150206_20150525 & -73.29 & 108 & $20150209 \_20150618$ & -10.90 & 129 \\
20150206_20150529 & 1.42 & 112 & $20150209 \_20150621$ & -263.98 & 132 \\
20150222_20150525 & 209.29 & 92 & $20150313 \_20150617$ & -451.66 & 96 \\
20150222_20150529 & 284.01 & 96 & $20150329 \_20150520$ & -63.86 & 52 \\
20150310_20150525 & 500.18 & 76 & $20150329 \_20150601$ & 620.62 & 64 \\
20150326_20150522 & -291.46 & 57 & $20150329 \_20150621$ & 600.21 & 84 \\
20150411_20150525 & -267.14 & 44 & & & \\
\hline
\end{tabular}

During the generation of InSAR and MAI interferograms, sixteen looks in the range and azimuth dimensions were applied for noise reduction and enhancement of computational efficiency, respectively. Using the multi-looking process, the final MAI and InSAR interferograms have approximately $32 \mathrm{~m}$ pixel spacing, whereas the pixel spacing of the SLC image is approximately $2 \mathrm{~m}$ in the range and azimuth dimensions. As already demonstrated by previous studies, the accuracy of the MAI phase depends primarily on the interferometric coherence of the forward- and backward-looking interferograms. Interferometric coherence, in turn, can be improved through the multi-looking and phase filtering process of an interferogram. Thus, accurate along-track displacements were obtained by applying multi-looking and phase filtering to the sub-aperture interferograms before creating the final MAI interferogram. In addition, we used multi-temporal SAR acquisitions for stacking co-eruptive interferograms. Similar to the noise reduction by multi-looking process, stacking of multiple observations enabled us to measure the precise and accurate surface displacements in both line-of-sight (LOS) and along-track directions. The InSAR stacking was performed by averaging all the InSAR interferograms, whereas the MAI stacking was carried out according to the recently proposed optimal MAI stacking approach [16]. The topographic phase contributions were removed using the simulated interferogram from the SRTM digital elevation model (DEM). The DEM, with a resolution of $30 \mathrm{~m}$, was interpolated to approximately $15 \mathrm{~m}$ to match the pixel spacing of the interferograms after the first multi-looking process.

To measure MAI deformation using COSMO-SkyMed SAR data, it was necessary to correct the phase oscillation along the azimuth direction. Unlike other SAR images, a COSMO-SkyMed MAI interferogram exhibits an additional oscillation phase pattern. The fluctuation range of this sinusoidal phase is approximately \pm 0.044 radians. This corresponds to an approximately $\pm 4 \mathrm{~cm}$ displacement in the along-track direction. We did not identify the main reason for phase oscillation in the along-track direction, but the most likely causes are a clock error in the satellite or an oscillation in the altitude of the satellite. The magnitude of the fluctuation is approximately $\pm 4 \mathrm{~cm}$, but the oscillation phase patterns were different in each MAI interferogram. We attempted to correct the oscillation phase with its own values for each MAI interferogram. The phase screen for the correction was computed by averaging the uncorrected MAI phase with the range direction within the stable region. Some residual errors remained after this approach, but they were reduced in further processing via stacking. 
The 3D components of surface deformation were retrieved by combining multi-stacked InSAR and MAI measurements from ascending and descending data sets. The east $\left(u_{e}\right)$, north $\left(u_{n}\right)$, and up $\left(u_{u}\right)$ components were retrieved using the equations defining $\operatorname{InSAR}\left(d_{l o s}\right)$ and MAI $\left(d_{\text {MAI }}\right)$ measurements in previous studies [9].

$$
\begin{gathered}
\left(u_{n} \sin \varphi-u_{e} \cos \varphi\right) \sin \theta+u_{u} \cos \theta=d_{l o s} \\
u_{n} \cos \varphi+u_{e} \sin \varphi=d_{M A I}
\end{gathered}
$$

where the track angles $(\varphi)$ of $-10.53^{\circ}$ and $-169.58^{\circ}$ and look angles $\theta$ of $38.76^{\circ}$ and $41.34^{\circ}$ were used for the ascending and descending data, respectively.

\section{Three-Dimensional Measurements}

Figure 2 shows the along-track and cross-track (LOS) displacements obtained by the stacks of multiple InSAR pairs. Eight and seven pairs were stacked for the ascending and descending data sets, respectively. The measurements in the low-coherence $(\gamma<0.7)$ areas were masked due to their low reliability. As shown in Figure 2a,c, the LOS deformation based on the InSAR method were clearer than the along-track deformation in Figure 2b,d. In general, the InSAR measurements are much more precise than the MAI measurements. However, previous studies have shown that the MAI interferograms can provide measurement accuracies of approximately $1.0 \mathrm{~cm} /$ year by stacking multi-temporal pairs [16,17]. Moreover, MAI measurements might provide more reliable results than InSAR in certain places where atmospheric effects are severe because the MAI technique is not influenced by atmospheric signal delay [16].

As observed in the InSAR measurements of both ascending and descending data sets, uplift is clearly identified in the vicinity of Kîlauea's summit, but the center of the deformed region is separated from the Killauea caldera to the southwest. The along-track deformation from both ascending and descending data sets shows a symmetric deformation pattern in opposite directions in the northern and southern portions from the deformation center (Figure 2b,d). The along-track displacement from the ascending data shows an oblique distribution pattern, whereas this pattern is not clearly visible in the descending data set. Therefore, the deformation source is not uniaxial but might be bi- or triaxial in shape. The magnitudes of the deformation are nearly the same in both data sets. The maximum displacement of the southern part of the caldera in the along-track direction is approximately $16 \mathrm{~cm}$, based on the results from both data sets.

Two LOS and two along-track displacements from ascending and descending data were jointly inverted to retrieve the east, north, and up components of the 3D deformation around Kîlauea's summit area (Figure 3). Positive values represent movement in the eastward, northward, and upward directions. The maximum displacements measured are approximately $8.2,-13.8$, and $11.6 \mathrm{~cm}$ in the east, north, and up directions, respectively. As with the individual InSAR and MAI measurements, the typical deformation pattern for the summit's inflation can be observed via the 3D displacement maps. These maps also show that the center of the uplift was not exactly in center of the caldera, whereas the deflation center in association with the Kamoamoa fissure eruption was nearly in the center of the caldera. Therefore, the magma sources for the Kamoamoa fissure eruption and the recent intrusion 
were not the same. The magma source for the recent intrusion is slightly separated from the caldera center in the southwestward direction

Figure 4 shows the 3D displacement vectors computed by combining the eastward and northward components of the 3D deformation. Arrows indicate the horizontal movements, and the color map represents the vertical component of the surface deformation. Based on the horizontal vector fields, the pattern of surface inflation is clearly recognizable. The difference is not great, but the movement in the north-south direction is more distinct than that in the east-west direction. As discussed earlier, this means that the magma source for this intrusion is likely not spherical in shape. The 3D measurements enable us to assume the approximate shape and size of the deformation source. These estimates, in turn, are used as an initial parameter determination in modeling.
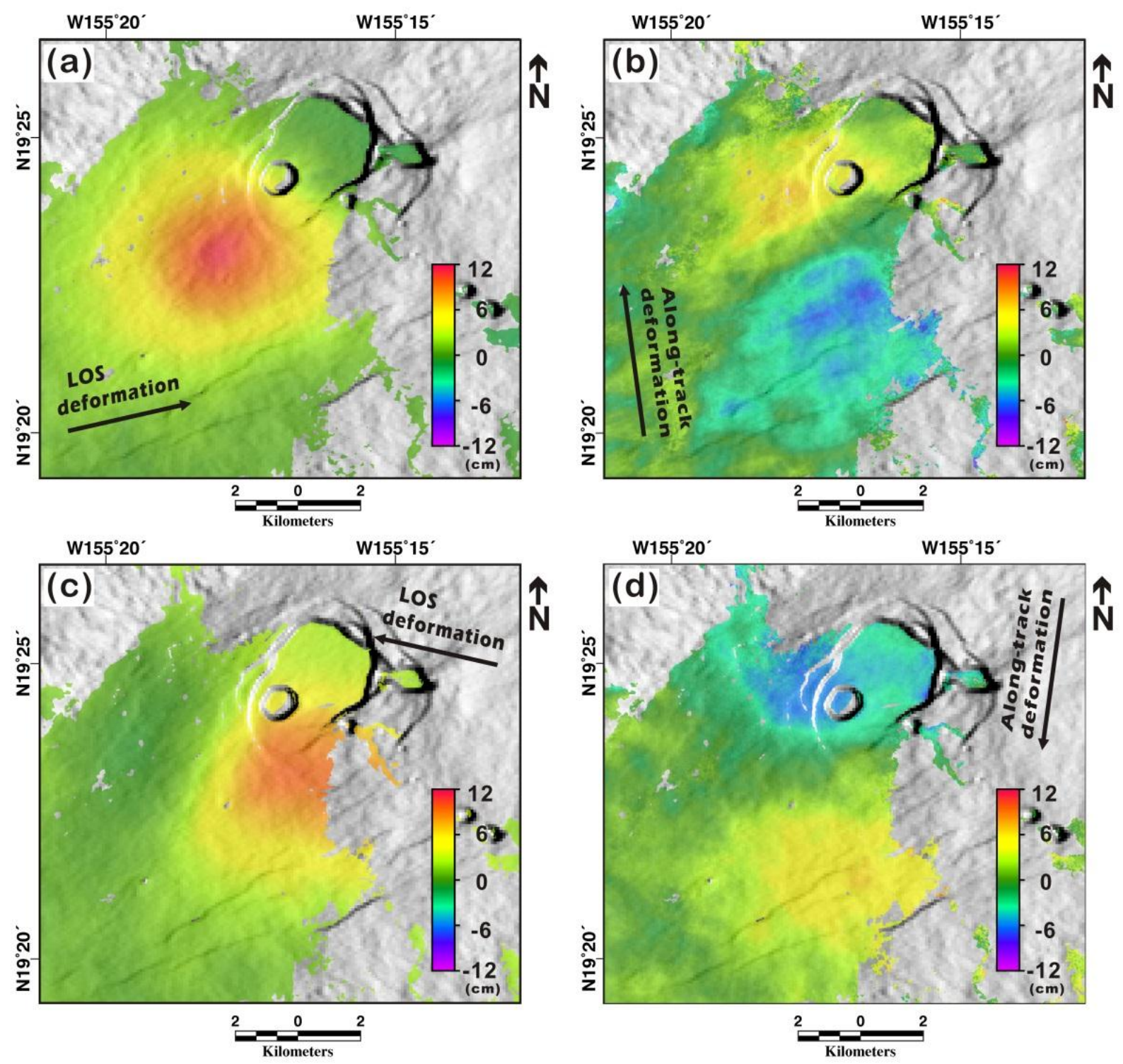

Figure 2. Multi-stacked InSAR and MAI measurements. (a) LOS and (b) along-track deformation based on InSAR and MAI measurements from ascending orbits. (c) LOS and (d) along-track deformation based on InSAR and MAI measurements from descending orbits. 

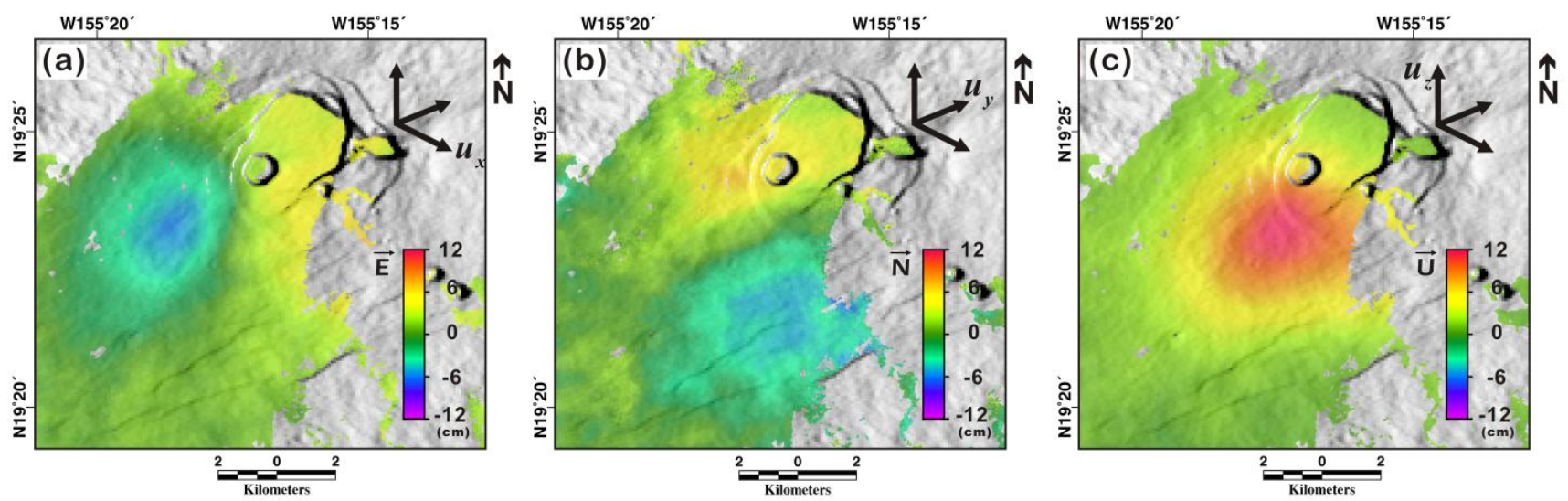

Figure 3. 3D surface displacement maps retrieved from integrating multi-stacked InSAR and MAI measurements: (a) east, (b) north, and (c) up components of surface deformation. Positive signals represent eastward, northward, and upward movements.

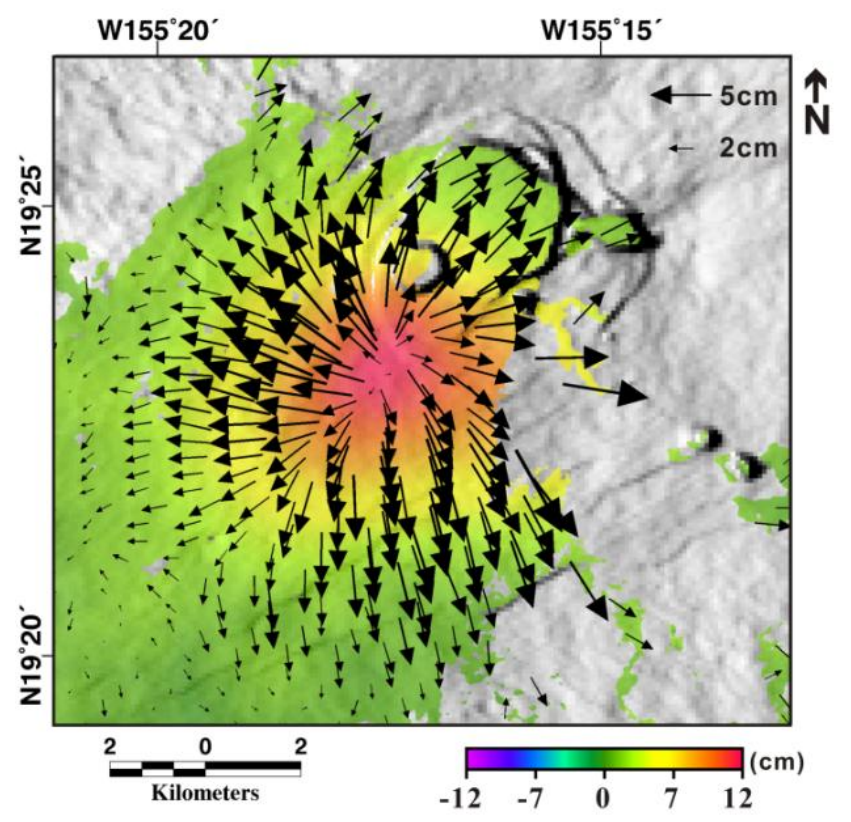

Figure 4. The horizontal displacement vector field generated from the east and north components of surface deformation. The arrows indicate the magnitude and directions of the horizontal displacements, and the colored map represents the vertical displacements.

\section{Magma Source Modeling}

To define the magma source inducing the surface deformation at Kîlauea's summit for the recent intrusion in April-May 2015, we applied the prolate spheroid model (Yang model) [24] and rectangular dislocation model (Okada model) [26], assuming an isotropic, homogeneous, and elastic half-space condition. We assumed a Poisson's ratio of 0.25 . To determine the optimal parameters of the magma source, we performed ten thousand simulations via Monte Carlo optimization. All model parameters were not fixed, and each of them was determined between the boundary conditions. Among the total of over 400,000 pixels within the deformation maps, $7 \%$ from randomly selected samples 
were used for the model parameter estimation in each iteration. The upper and lower boundaries of the model parameters were broadly chosen by referencing previous modeling from other studies. The optimum model parameters of the magma source were determined as the model with the minimum misfit.

Based on the 3D measurements of surface deformation, we expect that the magma source inducing this minor event should be appropriately modeled by a spheroid model. However, we exploited the dislocation model as well, in order to compare the two modeled results. Additionally, a previous study simulated a magma source using the dislocation model for deformation measured in almost the same position as our observations [20]. Among the four distinct magma sources below the Kîlauea summit, the deformation patterns and location in this study are quite similar to the surface deformation observed during the period of March 2006 to October 2006 [20].

Figure 5 shows the inversion results of the dislocation model using 3D displacement maps, reporting the observed (left), modeled (center), and residual (right) displacements for the east, north, and up components. The 3D components were jointly modeled to determine the parameters of the magma source inducing the surface changes. Based on the residual displacement maps in Figure 5, a few centimeters of residuals were observed in the east, north, and up components. The root-mean-square (RMS) values for the residual displacements were $0.88,1.03$, and $0.54 \mathrm{~cm}$ for the east, north, and up components, respectively. Based on the RMS estimation, the residuals of the north component are slightly larger than those of the east and up components, but the RMS ratios between the residual and observed displacements of the east and north components were similar, with values of 0.49. The residual of the observation ratio for the up component $(0.18)$ was the smallest among the $3 \mathrm{D}$ components. In other words, much of the noise might be introduced by measuring the horizontal displacements. Since the up component is only relevant to the InSAR measurement, we infer that the MAI observation introduced the majority of the errors.

The best-fit parameters based on the dislocation model are summarized in Table 2. Based on the results of the 3D-based modeling, the estimated magma source has a dimension of approximately 4.02 $\mathrm{km}$ in width and $1.61 \mathrm{~km}$ in length. The orientation of this rectangular source is approximately N67E, and the dip angle is small enough to be considered horizontal. The depth of the magma reservoir is approximately $4.25 \mathrm{~km}$ below the surface. [20] estimated the depth of this deep source to be $2.9-4.2 \mathrm{~km}$ at the $95 \%$ confidence level, and their best-fit estimate of depth was approximately $3.6 \mathrm{~km}$. When compared to the results of [20], our modeled source is at a reasonable depth but slightly deeper than that of the previous study. The volume change in the magma source differed significantly from the estimate of the previous study. Assuming a uniform dislocation from the overall rectangular magma source, the estimated volume increase is approximately $6.03 \times 10^{6} \mathrm{~m}^{3}$ using the width, length, and opening model parameters. This value is almost half the size of the volume change in the previous study [20]. Based on the difference in volume changes, we confirmed that the scale of the previous intrusion was much larger than that of the recent event. This finding is further supported by the different durations of the intrusions. The previous intrusion lasted for approximately six months (28 March to 6 October 2006) [20], whereas this minor event lasted only approximately two weeks. 

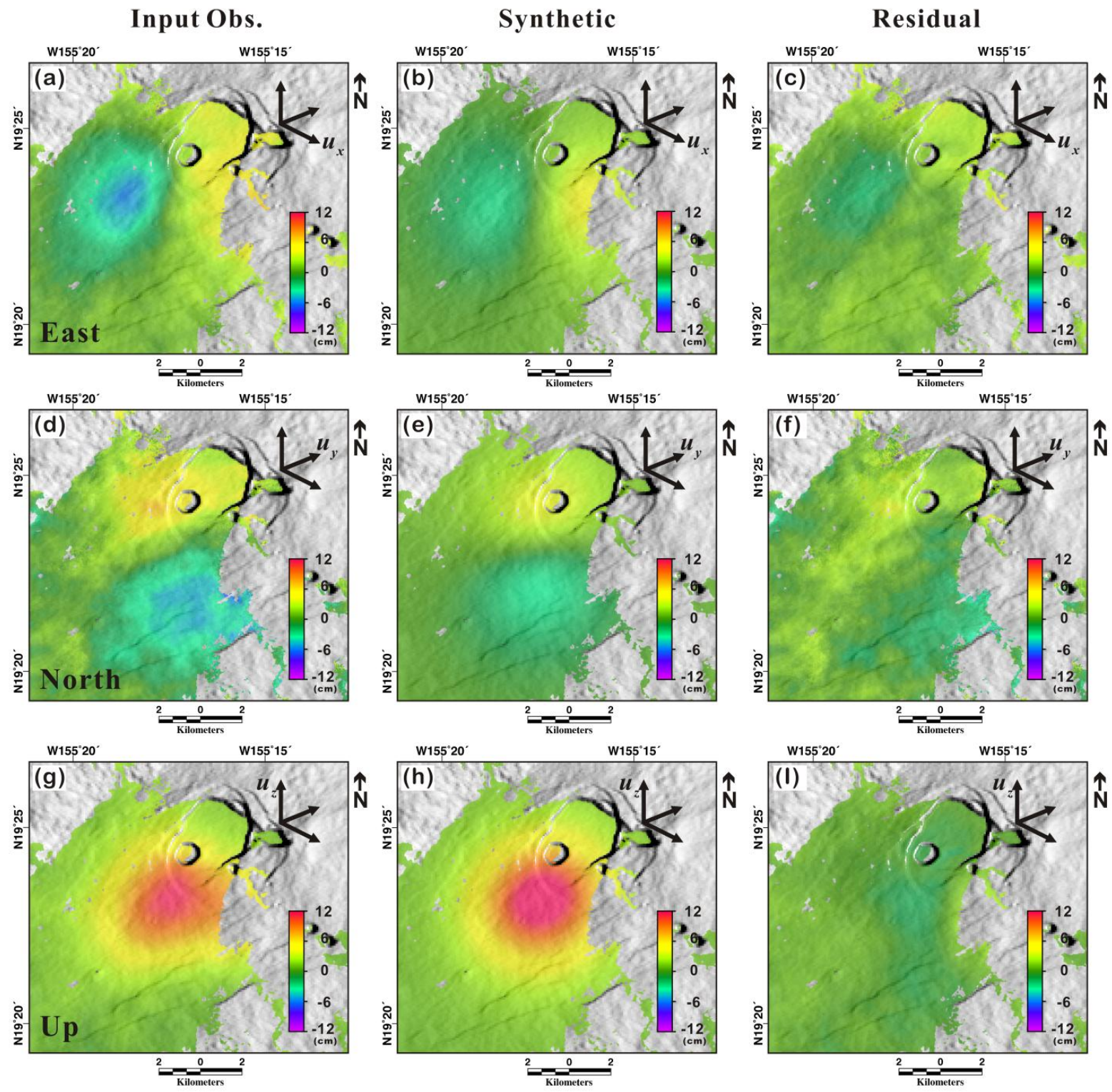

Figure 5. Inversion results of the rectangular dislocation (Okada) model for Kîlauea's summit area using 3D measurements. The first row shows the (a) observed, (b) synthetic, and (c) residual deformation of the east component. The second row shows the (d) observed (e) synthetic, and (f) residual deformation of the north component. The third row shows the (g) observed, (h) synthetic, and (i) residual deformation of the up component.

Table 2. The best-fit model parameters of Kîlauea's magma source using the Okada dislocation model.

\begin{tabular}{|c|c|c|c|c|c|c|c|c|c|}
\hline \multirow[b]{2}{*}{$\begin{array}{c}\text { Width } \\
(\mathbf{k m})\end{array}$} & \multicolumn{9}{|c|}{ Okada Model Parameters } \\
\hline & $\begin{array}{c}\text { Length } \\
(\mathbf{k m})\end{array}$ & $\begin{array}{c}\text { Depth } \\
(\mathbf{k m})\end{array}$ & $\begin{array}{l}\text { Dip*** } \\
\text { (deg.) }\end{array}$ & $\begin{array}{l}\text { Strike } \\
\text { (deg.) }\end{array}$ & $\begin{array}{c}\text { Pos-X* } \\
\text { (lon.) }\end{array}$ & $\begin{array}{c}\text { Pos-Y* } \\
\text { (lat.) }\end{array}$ & $\begin{array}{l}\text { Strike-Slip } \\
\left(\mathbf{x 1 0 ^ { - 0 3 }} \mathbf{k m}\right)\end{array}$ & $\begin{array}{c}\text { Dip-Slip } \\
\left(\mathbf{x 1 0 ^ { - 0 3 }} \mathbf{k m}\right)\end{array}$ & $\begin{array}{c}\text { Opening } \\
\left(\mathbf{x 1 0}^{-03} \mathbf{k m}\right)\end{array}$ \\
\hline $\begin{array}{c}4.019 \pm \\
0.08\end{array}$ & $\begin{array}{c}1.612 \pm \\
0.16\end{array}$ & $\begin{array}{c}4.247 \pm \\
0.05\end{array}$ & $\begin{array}{c}4.757 \pm \\
0.41\end{array}$ & $\begin{array}{l}67.475 \\
\pm 1.02\end{array}$ & $\begin{array}{c}-155.287 \pm \\
7.31 \mathrm{e}^{-04}\end{array}$ & $\begin{array}{c}19.382 \pm \\
0.13\end{array}$ & $\begin{array}{l}0.0165 \pm \\
9.24 \mathrm{e}^{-06}\end{array}$ & $\begin{array}{c}0.0055 \pm \\
1.24 \mathrm{e}^{-05}\end{array}$ & $\begin{array}{c}0.9314 \pm \\
9.56 \mathrm{e}^{-05}\end{array}$ \\
\hline
\end{tabular}

* The ground coordinates at the origin (top left-hand corner) of the $\mathrm{X}$ and $\mathrm{Y}$ axes are $-155.35208^{\circ}$ and $19.44708^{\circ}$, respectively. ${ }^{*}$ The angle between the model and a horizontal plane ( 0 to 90$)$. 

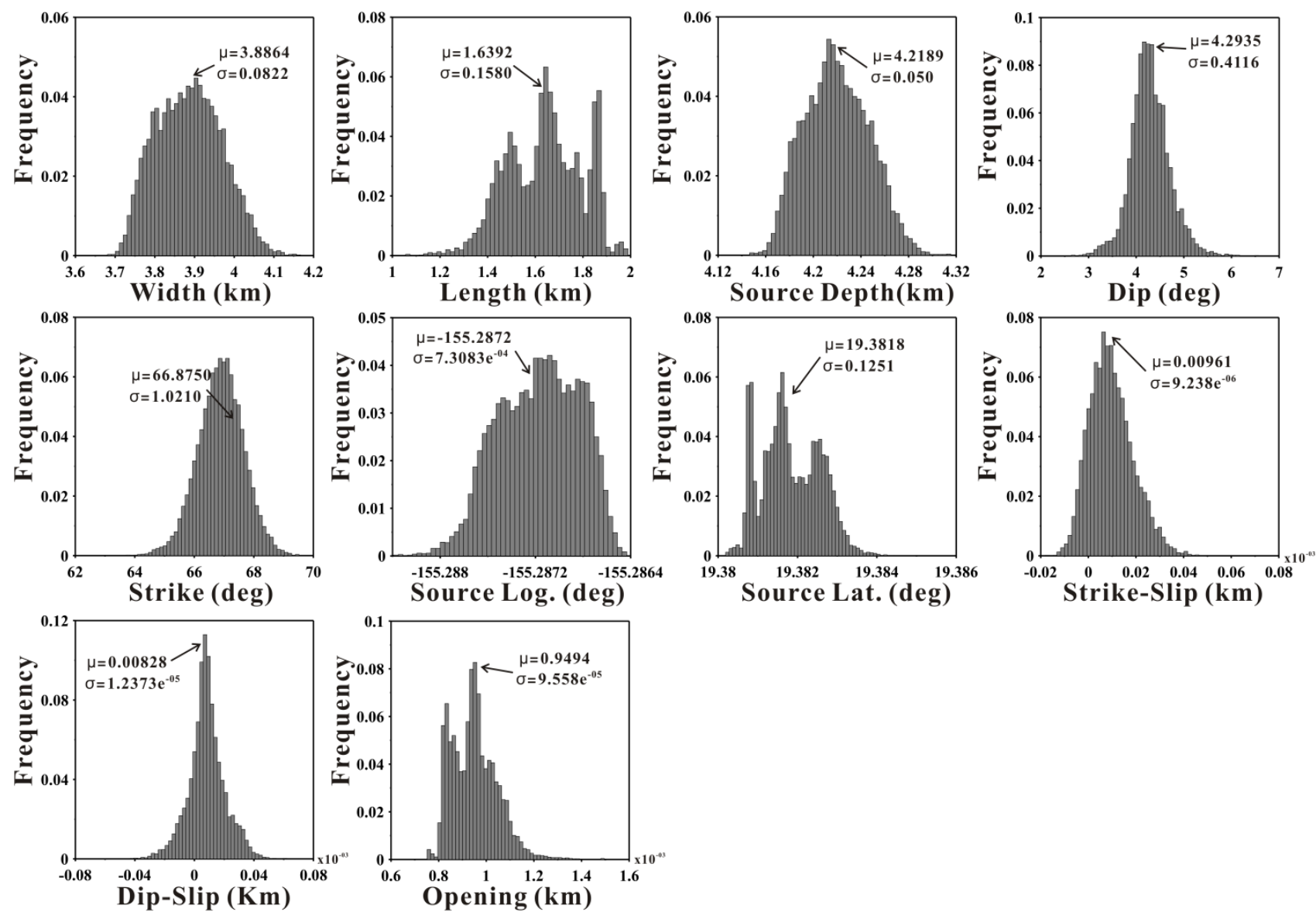

Figure 6. Histograms of the magma source parameters estimated from the 3D measurement inputs using the Okada dislocation model.

Based on the dislocation model, the best-fit $\mathrm{X}$ and $\mathrm{Y}$ positions of the magma source were approximately -155.287 and 19.382 degrees in the ground coordinates, which differ slightly from the results in the previous study (-155.29 degrees longitude and 19.38 degrees latitude) [20]. As observed in the histograms of the model parameters in the Okada model (Figure 6), the $\mathrm{X}$ and $\mathrm{Y}$ positions (longitude and latitude coordinates) did not simply converge on a unique value. In particular, the parameter of the Y-position featured a multimodal histogram with relatively large uncertainties. The length and opening parameters also showed multiple peaks with large standard deviations. Although several parameters did not converge on a unique solution due to relatively large uncertainties, the $3 \mathrm{D}$ measurements provided an improved magma source model relative to the InSAR measurements by reducing biases. The enhancement of the parameter estimation for the magma source model using 3D measurements was demonstrated by [17].

Figure 7 shows the inversion results of the prolate spheroid model from the 3D displacement maps. In Figure 7, the left column is the inputs of east, north, and up components, which are the same as the dislocation model. The center and right columns are synthetic and residual displacements based on the spheroid model, respectively. When the results of the dislocation model are compared to those of the spheroid model, the residuals were small, demonstrating that the magma model is accurately estimated by the spheroid model. The RMS estimates of the residual displacements were $0.81,0.79$, and $0.41 \mathrm{~cm}$ 
for the east, north, and up components, respectively. Among the 3D components, the residuals of the north component notably decreased by approximately 23\%. Therefore, the spheroid magma source matches the 3D measurements and provides the most realistic magma model for the recent magma intrusion. Similar to the north component, the residuals of the east and up components were lower in the spheroid model than in the dislocation model. The residual to observation ratios for the east, north, and up components were approximately $0.45,0.37$, and 0.13 , respectively.

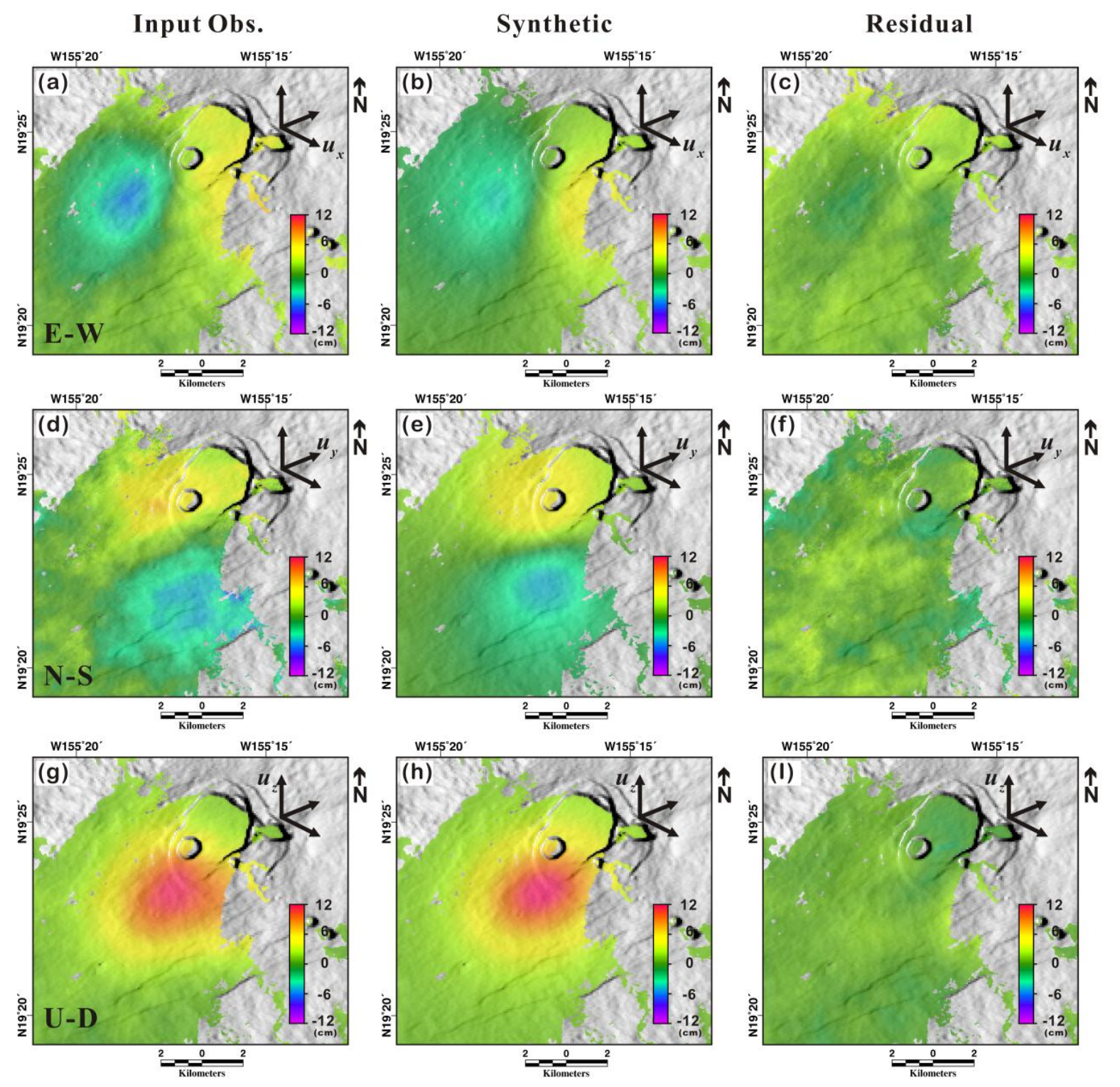

Figure 7. Inversion results of the prolate spheroid model for the magma source below Kinlauea's summit using 3D measurements. The first row shows the (a) observed, (b) synthetic, and (c) residual deformation of the east component. The second row shows the (d) observed (e) synthetic, and (f) residual deformation of the north component. The third row shows the (g) observed, (h) synthetic, and (i) residual deformation of the up component. 
The best-fit parameters of the spheroid model are summarized in Table 3. The magma source's X-and Y-positions, depth, pressure, major and minor axes, strike, and plunge were determined from the 3D-based modeling. The magma pressure estimated from the modeling has been converted to a volumetric change using the conversion equation in [27]. Although the $\mathrm{X}$ - and Y-positions of the magma source are similar to the best-fit model parameters of the dislocation model, i.e., -155.288 degrees longitude and 19.388 degrees latitude, the depth of the source, approximately $2.81 \mathrm{~km}$ below the surface, is quite different. The strike and plunge of the source were estimated to be approximately N64E and 8.3 degrees, respectively. The orientation angles of the two models are similar, differing by only approximately three degrees. The reservoir's volume change due to magma intrusion was calculated to be $5.20 \times 10^{6} \mathrm{~m}^{3}$ based on the estimated pressure change.

Table 3. The best-fit prolate spheroid model parameters of Kîlauea's magma source.

\begin{tabular}{|c|c|c|c|c|c|c|c|}
\hline \multicolumn{8}{|c|}{ Prolate Spheroid Model Parameters } \\
\hline $\begin{array}{c}\text { Pos-X* } \\
\text { (lon.) } \\
\end{array}$ & $\begin{array}{c}\text { Pos-Y* } \\
\text { (lat.) } \\
\end{array}$ & $\begin{array}{c}\text { Depth } \\
(\mathbf{k m}) \\
\end{array}$ & $\begin{array}{c}\text { Volume Change } \\
\left(\times 10^{6} \mathrm{~m}^{3}\right) \\
\end{array}$ & $\begin{array}{c}\text { Major } \\
\text { Axis (km) }\end{array}$ & $\begin{array}{c}\text { Minor } \\
\text { Axis (km) }\end{array}$ & $\begin{array}{l}\text { Strike } \\
\text { (deg.) }\end{array}$ & $\begin{array}{c}\text { Plunge } \\
\text { (deg.) }\end{array}$ \\
\hline $\begin{array}{c}-155.288 \pm \\
1.042 \mathrm{e}^{-04} \\
\end{array}$ & $\begin{array}{l}19.388 \pm \\
5.75 \mathrm{e}^{-05} \\
\end{array}$ & $\begin{array}{c}2.813 \pm \\
0.012 \\
\end{array}$ & $5.210 \pm 0.056$ & $\begin{array}{c}3.142 \pm \\
0.044 \\
\end{array}$ & $\begin{array}{c}2.139 \pm \\
0.048 \\
\end{array}$ & $\begin{array}{c}64.265 \pm \\
0.603 \\
\end{array}$ & $\begin{array}{c}8.306 \pm \\
0.464 \\
\end{array}$ \\
\hline
\end{tabular}

Figure 8 shows the histograms of the parameter estimations using a spheroid model. Ten thousand iterations were performed to determine the best-fit model parameters. Unlike the simulation results of the dislocation model, all the parameters converge on unique values with very small standard deviations. Therefore, the spheroid model is in good agreement with the magma source. In particular, the source position and orientation parameters are clearly determined by the spheroid model, unlike the parameters in the Okada model that exhibited multimodal histograms.
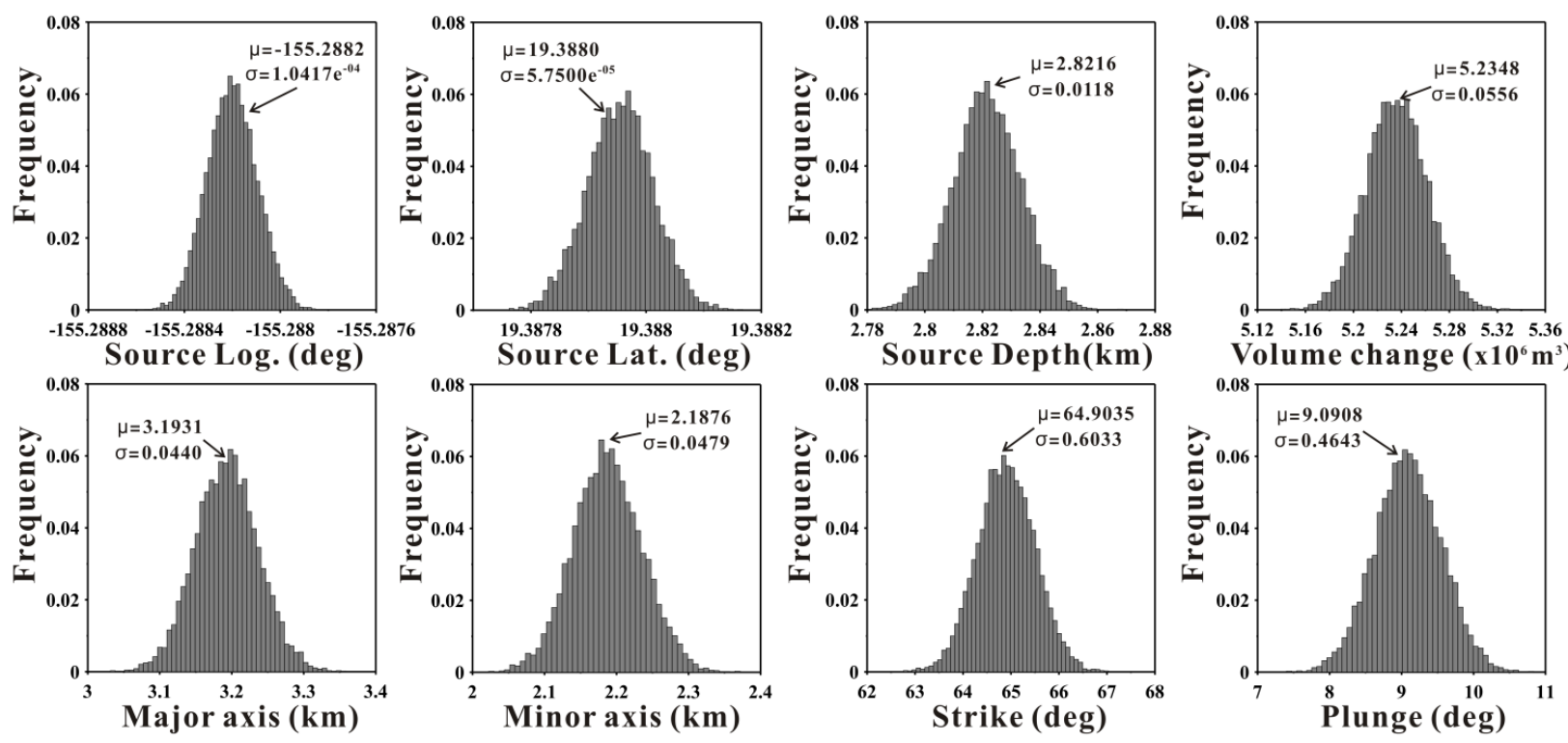

Figure 8. Histograms of the magma source parameters estimated from the 3D measurement inputs using prolate spheroid model. 
Based on the previous studies, at least three to four distinct magma sources are responsible for inducing uplift or deflation on Kilauea [7,16,20,22]. The magma source related to the recent magma intrusion is most likely coincides with the deep source located near the southwest rift zone, based on the deformation patterns and distribution. Figure 9 shows the refined magma source locations estimated from our 3D-based modeling and previously defined source locations from an earlier study [20]. The areas with colors represent the locations of sources below Kîlauea's summit. The extent of the color boundaries correspond to the uncertainty associated with each source location. In other words, a large area of color indicates a relatively uncertain location of the magma source.

In Figure 9, the source very close to the Halema'uma'u crater is the shallow magma reservoir, which lies at a depth of approximately 1.5-2.0 km below the surface [14,16,22]. Only this shallow reservoir is presumed to be a point source with a spherical or spheroid shape; the others located at depths of $2.5-4.0 \mathrm{~km}$ are presumed to be penny-shaped or rectangular sources. The magma source represented by the large light-red ellipsoid is the deepest source beneath Kilauea's summit and is related to the magma source involved in the recent volcanic event. The two small areas that are very close to the light-red ellipsoid are the magma source locations from our modeled results. These source locations do not differ significantly from the previous location, but much better precision can be obtained using 3D-based modeling. In particular, the 3D-based model based on a spheroid source provided almost identical source positions in ten thousand Monte-Carlo simulations. The ellipsoid with the dashed outline represents the modeled magma source with the best-fit model parameters based on a spheroid source. The best-fit spheroid model involves a magma body at approximately $2.8 \mathrm{~km}$ depth, which is $>1 \mathrm{~km}$ shallower than the previous estimate.

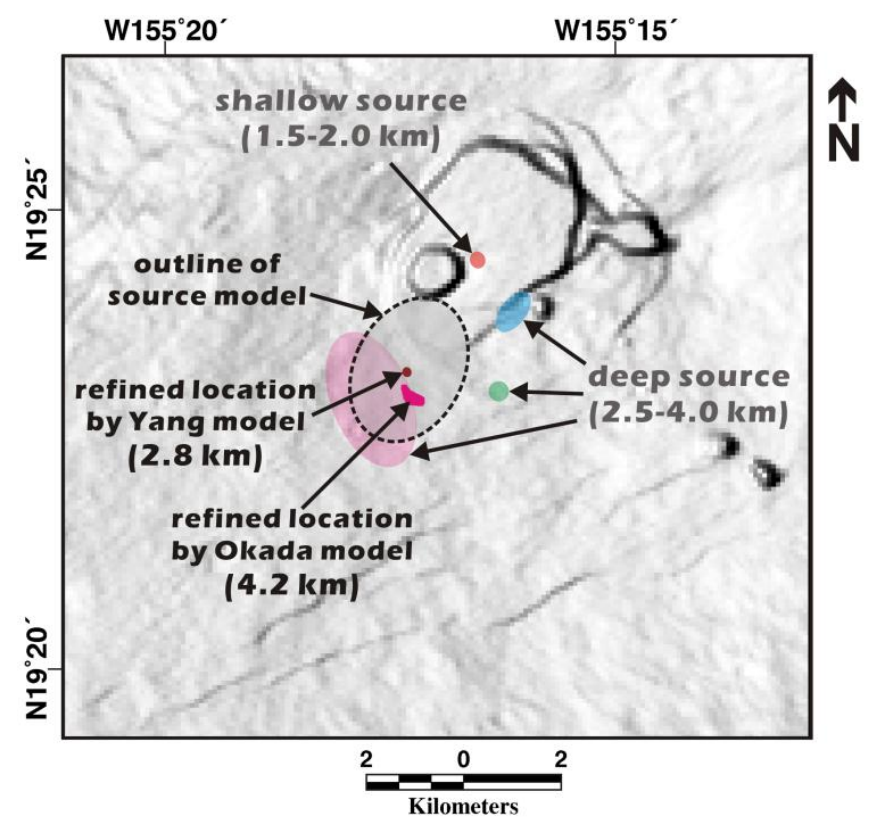

Figure 9. Refined magma source locations estimated from the 3D displacement maps using rectangular dislocation (Okada) model and prolate spheroid (Yang) model. Areas with colors indicate the source locations below Kîlauea's summit, as defined by a previous study [20] and our results. The dashed outline represents the magma source boundary of the spheroid model. 


\section{Conclusions}

We have retrieved 3D surface deformation components by integrating multi-stacked InSAR and MAI measurements of the deformation induced by recent magma intrusion at Kîlauea, Hawai' $i$. COSMO-SkyMed X-band SAR data from ascending and descending orbits was collected before and after the period of unrest from April to May 2015 to observe uplift associated with the intrusion of magma. From the 3D measurements, we clearly identified deformation patterns and the boundary of deformed regions, enabling us to identify the center of the deformation, which is located slightly to the south of the Kîlauea caldera. The maximum displacement induced by this volcanic event was approximately $8.2,-13.8$, and $11.6 \mathrm{~cm}$ in the east, north, and up directions, respectively.

In this study, model parameters of the magma reservoir have been estimated using 3D measurement inputs. Two different magma source models, the Okada and prolate spheroid models, were employed to determine the appropriate magma model for this minor event, and the best-fit model parameters were determined using ten thousand iterative simulations. Through comparison with the model parameters in previous studies, a similar position of the magma chamber was determined, but the uncertainties were markedly diminished through the modeling of the $3 \mathrm{D}$ measurement inputs. The source location based on the best-fit dislocation model is approximately -155.287 degrees longitude and 19.382 degrees latitude and lies at a depth of approximately $4.25 \mathrm{~km}$ beneath the surface. The source location of the best-fit spheroid model is approximately -155.288 degrees longitude and 19.388 degrees latitude. Although the depth of the dislocation model is quite similar to that in the previous investigation, the best-fit estimate of the spheroid model suggests a relatively shallow depth of the magma source, approximately $2.8 \mathrm{~km}$ beneath the surface. The source dimensions and depth are differ somewhat from the previous report, but they exist within a reasonable range.

This minor volcanic event is characterized by complex magma behavior during a short time period. Thus, it is not easy to define the characteristics of the magma source, and a certain risk of oversimplification exists in the model parameter estimation. However, we expect that measuring precise 3D displacements and magma model determinations will provide guidance as a first attempt for this volcanic event. If we update the geometry and the conditions of the magma source using 3D-based modeling, the results will be helpful in better understanding of complex magmatic systems.

\section{Acknowledgments}

This study was supported by the MSIP (Ministry of Science, ICT \& Future Planning) and NRF (National Research Foundation of Korea) under the Space Core Technology Development Program (project id: 2013M1A3A3A02042314) and was also funded by the Korea Meteorological Administration Research and Development Program under Grant KMIPA2015-3071. The COSMO-SkyMed data were provided courtesy of the Hawai'i Supersite and Italian Space Agency (ASI).

\section{Author Contributions}

Min-Jeong Jo and Hyung-Sup Jung designed the research, and organized the contents of the manuscript. Min-Jeong Jo processed and analyzed the data, and wrote the first draft of the manuscript. Hyung-Sup Jung collected the SAR data as the Hawaii Supersite user, and contributed to discussions 
and manuscript editing. Joong-Sun Won is an advisor, and provided the crucial comments for this work. All authors contributed to editing and preparing the review reports.

\section{Conflicts of Interest}

The authors declare no conflict of interest.

\section{References}

1. Rosen, P.A.; Hensley, S.; Zebker, H.A.; Webb, F.H.; Fielding, E.J. Surface deformation and coherence measurements of KîlaueaKîlauea Volcano, Hawaii, from SIR-C radar interferometry. J. Geophys. Res. 1996, 101, 23109-23125.

2. Amelung, F.; Jónsson, S.; Zebker, H.; Segall, P. Widespread uplift and "trapdoor" faulting on Galápagos volcanoes observed with radar interferometry. Nature 2000, 407, 993-996.

3. Lundgren, P.; Berardino, P.; Coltelli, M.; Fornaro, G.; Lanari, R.; Puglisi, G.; Sansosti, E.; Tesauro, M. Coupled magma chamber inflation and sector collapse slip observed with synthetic aperture radar interferometry on Mt. Etna volcano. J. Geophys. Res. 2003, 108, 2247.

4. Yun, S.; Segall, P.; Zebker, H. Constraints on magma chamber geometry at Sierra Negra Volcano, Gálapagos Islands, based on Insar observations. J. Volcanol. Geotherm. Res. 2006, 150, 232-243.

5. Lu, Z.; Dzurisin, D.; Biggs, J.; Wicks, C.; McNutt, S. Ground surface deformation patterns, magma supply, and magma storage at Okmok volcano, Alaska, from Insar analysis: 1. Intereruption deformation, 1997-2008. J. Geophys. Res. 2010, 115, B00B02.

6. Jung, H.-S.; Lu, Z.; Won, J.-S.; Poland, M.P.; Miklius, A. Mapping three-dimensional surface deformation by combining multiple-aperture interferometry and conventional interferometry: Application to the June 2007 eruption of Kīlauea Volcano, Hawaii. IEEE Geosci. Remote Sens. Lett. 2011, 8, 34-38.

7. Poland, M.P.; Miklius, A.; Sutton, A.J.; Thornber, C.R. A mantle-driven surge in magma supply to Kīlauea Volcano during 2003-2007. Nature Geosci. 2012, 5, 295-300.

8. Hu, J.; Ding, X.-L.; Li, Z.-W.; Zhu, J.-J.; Sun, Q.; Zhang, L. Kalman-filter-based approach for multisensor, multitrack, and multitemporal InSAR. IEEE Trans. Geosci. Remote Sens. 2013, 51, 4226-4239.

9. Wright, T.J.; Parsons, B.E.; Lu, Z. Toward mapping surface deformation in three dimensions using InSAR. Geophys. Res. Lett. 2004, 31, L01607.

10. Fialko, Y.; Simons, M.; Agnew, D. The complete (3-D) surface displacement field in the epicentral area of the 1999 Mw7.1 Hector Mine earthquake, California, from space geodetic observations. Geophys. Res. Lett. 2001, 28, 3063-3066.

11. Jung, H.-S.; Won, J.-S.; Kim, S.-W. An improvement of the performance of multiple-aperture SAR interferometry (MAI). IEEE Trans. Geosci. Remote Sens. 2009, 47, 2859-2869.

12. Bechor, N.B.; Zebker, H.A. Measuring two-dimensional movements using a single InSAR pair. Geophys. Res. Lett. 2006, 33, L16311.

13. Jónsson, S.; Zebker, H.; Segall, P.; Amelung, F. Fault slip distribution of the 1999 Mw 7.1 Hector Mine, California, earthquake, estimated from satellite radar and GPS measurements. Bull. Seismol. Soc. Amer. 2002, 92, 1377-1389. 
14. Jung, H.-S.; Yun, S.-H.; Jo, M.-J. An improvement of Multiple-Aperture SAR Interferometry performance in the presence of complex and large line-of-sight deformation. IEEE J. Sel. Top. Appl. Earth Observ. Remote Sens. 2015, 8, 1743-1752.

15. Hu, J.; Li, Z.; Ding, X.; Zhu, J.; Zhang, L.; Sun, Q. 3D coseismic displacement of 2010 Darfield, New Zealand earthquake estimated from multi-aperture InSAR and D-InSAR measurements. J. Geodesy 2012, 86, 1029-1041.

16. Jo, M.-J.; Jung, H.-S.; Won, J.-S.; Poland, M.P.; Miklius, A.; Lu, Z. Measurement of slow-moving along-track displacement from an efficient multiple-aperture SAR interferometry (MAI) stacking. J. Geodesy 2015, 89, 411-425.

17. Jo, M.-J.; Jung, H.-S.; Won, J.-S.; Lundgren, P. Measurement of three-dimensional surface deformation by Cosmo-SkyMed X-band radar interferometry: Application to the March 2011 Kamoamoa fissure eruption, Kīlauea Volcano, Hawai'i. Remote Sens. Environ. 2015, 169, 176-191.

18. Covello, F.; Battazza, F.; Coletta, A.; Lopinto, E.; Fiorentino, C.; Pietranera, L.; Valentini, G.; Zoffoli, S. COSMO-SkyMed an existing opportunity for observing the Earth. J. Geodyn. 2010, 49, 171-180.

19. Lundgren, P.; Poland, M.; Miklius, A.; Orr, T.; Yun, S.H.; Fielding, E.; Liu, Z.; Tanaka, A.; Szeliga, W.; Hensley, S., et al. Evolution of dike opening during the March 2011 Kamoamoa fissure eruption, Kīlauea Volcano, Hawai'i. J. Geophys. Res. 2013, 118, 897-914.

20. Baker, S.; Amelung, F. Top-down inflation and deflation at the summit of Kîlauea Volcano, Hawai'i observed with InSAR. J. Geophys. Res. 2012, 117, B12406.

21. Montgomery-Brown, E.K.; Segall, P.; Miklius, A. KīlaueaKīlauea slow slip events: Identification, source inversions, and relation to seismicity. J. Geophys. Res. 2009, 114, B00A03.

22. Montgomery-Brown, E.K.; Sinnett, D.K.; Poland, M.; Segall, P.; Orr, T.; Zebker, H.; Miklius, A. Geodetic evidence for en echelon dike emplacement and concurrent slow slip during the June 2007 intrusion and eruption at Kīlauea volcano, Hawaii. J. Geophys. Res. 2010, 115, B07405.

23. Patrick, M.R.; Orr, T.; Sutton, A.J.; Tamar, E.; Swanson, D. The first five years of Kîlauea's summit eruption in Halema'uma'u Crater, 2008-2013. U.S. Geol. Surv. Fact Sh. 2013, 3116, 4.

24. Yang, X.M.; Davis, P.M.; Dieterich, J.H. Deformation from inflation of a dipping finite prolate spheroid in an elastic half-space as a model for volcanic stressing. J. Geophys. Res. 1988, 93, 4249-4257.

25. Poland, M.P.; Sutton, A.J.; Gerlach, T.M. Magma degassing triggered by static decompression at Kīlauea Volcano, Hawai‘i. Geophys. Res. Lett. 2009, 36, L16306.

26. Okada, Y. Surface deformation due to shear and tensile faults in a half-space. Bull. Seismol. Soc. Amer. 1985, 75, 1135-1154.

27. Battaglia, M.; Cervelli, P.F.; Murray, J.R. Modeling crustal deformation near active faults and volcanic centers-A catalog of deformation models. U.S. Geol. Surv. Tech. Method. 2013, 13-B1, 96.

(C) 2015 by the authors; licensee MDPI, Basel, Switzerland. This article is an open access article distributed under the terms and conditions of the Creative Commons Attribution license (http://creativecommons.org/licenses/by/4.0/). 